\title{
Pulmonary Hypertension Related to Left-Sided Cardiac Pathology
}

\author{
Todd L. Kiefer and Thomas M. Bashore \\ Division of Cardiology, Duke University Medical Center, P.O. Box 3102, Durham, NC 27710, USA \\ Correspondence should be addressed to Thomas M. Bashore, thomas.bashore@duke.edu
}

Received 10 January 2011; Revised 2 April 2011; Accepted 2 April 2011

Academic Editor: Aldo T. Iacono

Copyright (C) 2011 T. L. Kiefer and T. M. Bashore. This is an open access article distributed under the Creative Commons Attribution License, which permits unrestricted use, distribution, and reproduction in any medium, provided the original work is properly cited.

\begin{abstract}
Pulmonary hypertension $(\mathrm{PH})$ is the end result of a variety of diverse pathologic processes. The chronic elevation in pulmonary artery pressure often leads to right ventricular pressure overload and subsequent right ventricular failure. In patients with leftsided cardiac disease, $\mathrm{PH}$ is quite common and associated with increased morbidity and mortality. This article will review the literature as it pertains to the epidemiology, pathogenesis, and diagnosis of PH related to aortic valve disease, mitral valve disease, left ventricular systolic and diastolic dysfunction, and pulmonary veno-occlusive disease. Moreover, therapeutic strategies, which focus on treating the underlying cardiac pathology will be discussed.
\end{abstract}

\section{Introduction}

Pulmonary hypertension ( $\mathrm{PH})$ occurs with an overall prevalence estimated at 15 per one million individuals [1]. It is the end result of a variety of disparate pathophysiologic processes. Ultimately, these disease states lead to a spectrum of histopathologic lesions in the pulmonary vasculature with differing degrees of hypertrophy of the medial layer of the vessel wall, hyperplasia of the intimal layer, proliferation of the adventitial layer, and/or plexiform lesions [1]. These changes in the structure of the pulmonary arterial vascular bed lead to resistance to blood flow, and correspondingly, increased right ventricular (RV) pressures often leading to RV pressure overload with eventual RV failure.

The most up-to-date classification system categorizing patients with $\mathrm{PH}$ into groups based on the underlying disease process leading to $\mathrm{PH}$ was published in the European Society of Cardiology Guidelines in 2009 (Table 1) [2]. Of these groups, patients with Group $1 \mathrm{PH}$, not including pulmonary venoocclusive disease (PVOD), have been most extensively studied in pharmacotherapy clinical trials. In addition, $\mathrm{PH}$ is very common in patients with left-sided cardiac disease and has been reported in greater than $60 \%$ of patients with left ventricular systolic dysfunction, greater than $80 \%$ of patients with left ventricular diastolic dysfunction, and in $78 \%$ of patients prior to mitral valve surgery [3-6].
This article will review the current literature pertaining to $\mathrm{PH}$ secondary to left-sided cardiac disease (Group $2 \mathrm{PH}$ ), including PVOD (classified as Group 1' $\mathrm{PH}$ ), pulmonary vein stenosis, mitral stenosis (MS), mitral regurgitation (MR), aortic stenosis (AS), aortic regurgitation (AR), and left ventricular systolic/diastolic dysfunction (Figure 1). In addition, it is worth mentioning that a web membrane, between the pulmonary veins and the left atrial chamber, (cor triatriatum sinister) and left ventricular inflow obstruction from a left atrial myxoma have also been associated with pulmonary hypertension. Other lesions that place a pressure overload on the left ventricle (LV), such as systemic hypertension, and the rare clinical entities of coarctation of the aorta, supravalvular aortic stenosis, and a subaortic membrane, have been reported in association with PH. However, they will not be discussed in detail individually.

\section{Diagnosis}

Consensus guidelines define pulmonary arterial hypertension $(\mathrm{PAH})$ as a mean pulmonary artery (PA) pressure greater than $25 \mathrm{~mm} \mathrm{Hg}$ in the setting of a pulmonary capillary wedge pressure (PCWP), left atrial (LA) pressure, or left ventricular end-diastolic pressure (LVEDP) less than or equal to $15 \mathrm{~mm} \mathrm{Hg}$ [2]. Meanwhile, the term $\mathrm{PH}$, in a less specific 
TABLE 1: Classification system of pulmonary hypertension into groups 1-5 based on underlying disease process.

\begin{tabular}{|c|c|c|c|c|c|}
\hline Group 1 & Group $1^{\prime}$ & Group 2 & Group 3 & Group 4 & Group 5 \\
\hline $\begin{array}{l}\text { (i) Idiopathic } \\
\text { (ii) Familial } \\
\text { (iii) Connective tissue diseases } \\
\text { (iv) Congenital shunt lesions } \\
\text { (v) HIV } \\
\text { (vi) Drugs/Toxins } \\
\text { (vii) Hemoglobinopathies } \\
\text { (viii) Portal hypertension } \\
\text { (ix) Persistent pulmonary } \\
\text { hypertension of the newborn }\end{array}$ & PVOD & $\begin{array}{l}\text { (i) Left ventricular } \\
\text { systolic/diastolic } \\
\text { dysfunction } \\
\text { (ii) Left-sided } \\
\text { valvular dysfunction }\end{array}$ & $\begin{array}{l}\text { Chronic lung } \\
\text { diseases and/or } \\
\text { hypoxemia }\end{array}$ & $\begin{array}{l}\text { Chronic } \\
\text { thromboembolic } \\
\text { disease }\end{array}$ & $\begin{array}{l}\text { Miscellaneous } \\
\text { (i) Sarcoid } \\
\text { (ii) Histiocytosis X } \\
\text { (iii) Fibrosing mediastinitis } \\
\text { (iv) Myeloproliferative } \\
\text { disorders } \\
\text { (v) Metabolic storage diseases } \\
\text { (vi) Thyroid disease }\end{array}$ \\
\hline
\end{tabular}

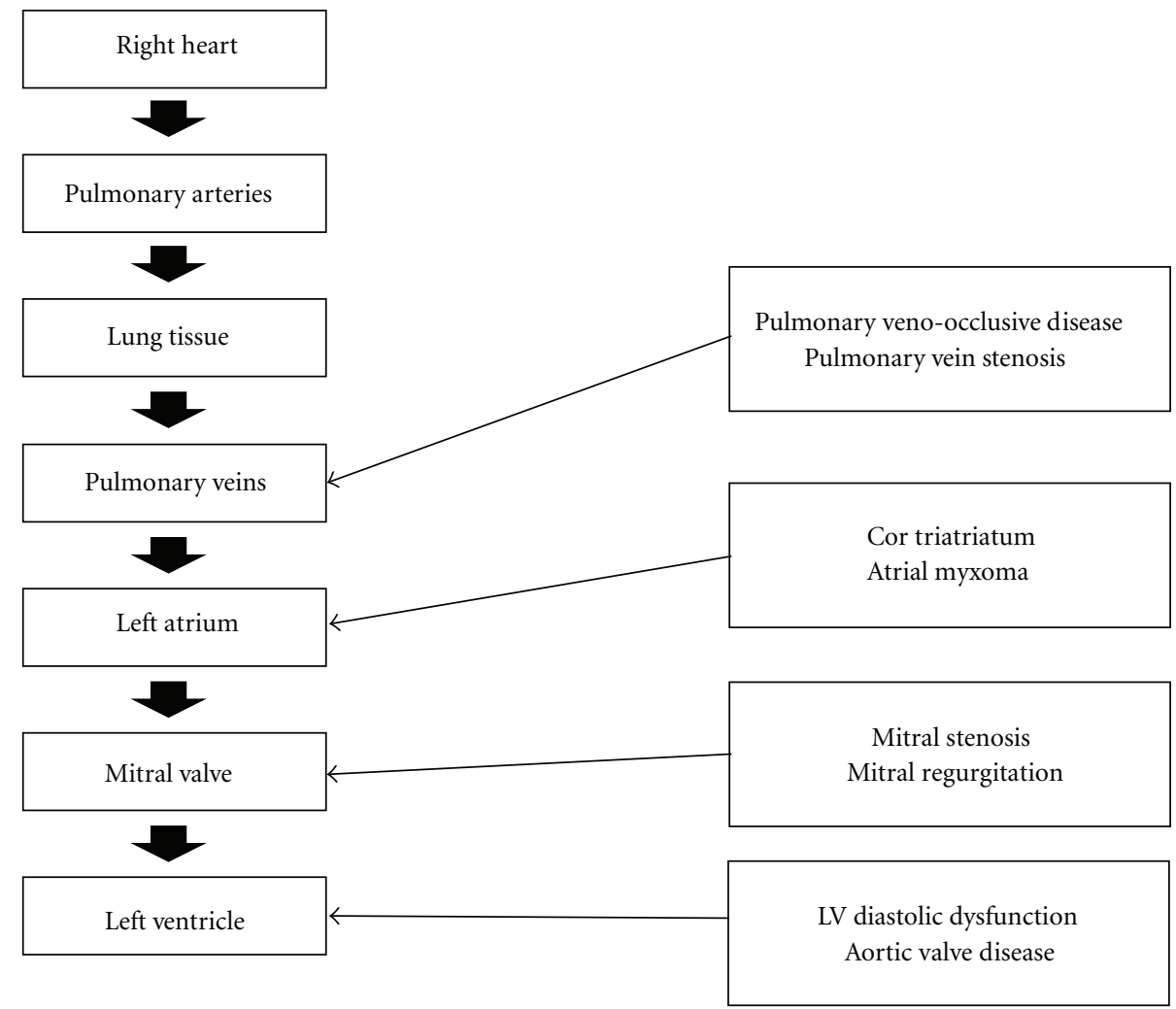

Figure 1: Anatomic organization of left heart causes of pulmonary hypertension from the right ventricle through the lungs to the left ventricular outflow tract.

manner, refers to a mean PA pressure $>25 \mathrm{~mm} \mathrm{Hg}$ due to any cause [2].

Transthoracic echocardiography is recommended as a screening test in the evaluation of suspected $\mathrm{PAH}$, and this will provide essential information regarding concomitant left-sided valvular or ventricular dysfunction [1]. In some instances, however, invasive hemodynamic evaluation with right heart catheterization is required to confirm the diagnosis as echocardiography often underestimates the PA pressures and does not provide an accurate assessment of PCWP [1].

Careful analysis of the invasive hemodynamic data is critical to making a correct diagnosis and recommending the appropriate therapeutic options. As will be discussed in detail in following sections, the vast majority of patients with $\mathrm{PH}$ in the setting of an elevated PCWP should not be treated with $\mathrm{PAH}$ vasodilator therapies. In order to ensure the accuracy of the PCWP data, close attention should be given to the fidelity of the a-, c-, and v-wave morphologies on the PCWP hemodynamic tracing. Furthermore, the PCWP should be measured at end-expiration (intrapleural pressure is about $-5 \mathrm{~mm} \mathrm{Hg}$ at that point). If there is any question about the PCWP validity, then some advocate a PCWP wedge saturation (it should be similar to pulmonary venous saturation if done properly) and/or direct measurement of the LVEDP for confirmation.

Vasodilator challenge is an integral element in the assessment of suspected PAH and should be conducted for 
patients with a mean PA pressure $\geq 25 \mathrm{~mm} \mathrm{Hg}$ and a PCWP $\leq 15 \mathrm{~mm} \mathrm{Hg}$. For patients with a PCWP $>15 \mathrm{~mm} \mathrm{Hg}$, vasodilator testing should generally not be performed, or if it is performed, then it should be done with close hemodynamic monitoring by experienced clinicians with expertise in the evaluation of $\mathrm{PAH}$ due to the risk for development of acute pulmonary edema and sudden respiratory compromise. Approximately $10 \%$ of patients with $\mathrm{PAH}$ have a positive response to vasodilator challenge, defined as a decrease in mean PA pressure by $>10 \mathrm{~mm} \mathrm{Hg}$ to an absolute mean $<40 \mathrm{~mm} \mathrm{Hg}$ without a decrease in systemic blood pressure or cardiac output [2]. Inhaled nitric oxide, which has a very short half-life (15-30 seconds), is most frequently used to assess vasoreactivity $[2,7,8]$. Other agents including intravenous nitroprusside, epoprostenol, and adenosine have also been used for vasodilator response testing [2]. For patients with a cardiac shunt, nitroprusside should generally be avoided, as this agent is also a potent arterial vasodilator that will decrease systemic vascular resistance (SVR) and may facilitate right to left shunting leading to increasing hypoxemia.

\section{Obstruction to Pulmonary Venous Drainage}

Pulmonary venoocclusive disease (PVOD) is a rare entity characterized by obliterative fibrosis of small pulmonary veins [9]. It is estimated that PVOD occurs with a prevalence of $0.1-0.2$ per one million in the population and is the cause of $10 \%$ of the cases of PAH [9]. Significant morbidity and mortality is observed from PVOD-associated PAH with a one-year mortality of $72 \%$ [10]. Its cause is unknown but has been associated with viral infections and as a complication of certain diseases such as scleroderma, systemic lupus erythematosus, leukemia, chemotherapy, or bone marrow transplantation.

Given the relative infrequency of PVOD in the population, it is a challenging disease to characterize and study. Small studies have suggested a statistical association between PVOD among male gender and a history of smoking when compared to a population of idiopathic PAH patients [11]. The clinical presentation of PVOD varies but often includes dyspnea with exertion, hemoptysis, pulmonary edema, and $\mathrm{PAH}$. One clue is often the presence of segmental pulmonary edema-something that should not occur with idiopathic PAH. Otherwise, differentiating PAH due to PVOD from other causes based on clinical and noninvasive evaluation can be challenging. One study reported statistically lower $\mathrm{PaO} 2$ and DLCO values in PVOD compared with idiopathic PAH patients [11]. However, these are not specific findings unique to PVOD. In the past, lung ventilation-perfusion scanning was part of the diagnostic algorithm for the evaluation of suspected PVOD, but this is no longer recommended due to nonspecific findings and overlap with patterns of chronic thromboembolic disease [9]. Right heart catheterization demonstrates PAH but often with a lower mean PA systolic and mean RA pressure than in patients with idiopathic $\mathrm{PAH}$ [11]. The PCWP is often normal with a blunted waveform but should be carefully measured in multiple, bilateral lung zones as a notable difference in PCWP in one lung zone sug- gests PVOD. Thus, if PVOD is suspected, it is crucial at right heart catheterization that the PCWP be measured in both upper and lower lung fields. Wedge angiography can confirm the diagnosis (Figure 2). The wedge angiogram is performed using a balloon-tipped catheter and hand-injecting contrast media to fill the distal pulmonary arterial bed. Release of the balloon allows noncontrasted blood to wash out and opacify the pulmonary venous system. By assessing the pulmonary venous system in each quadrant, failure to visualize the respective pulmonary vein in a quadrant is diagnostic of the disease. Additionally, when PVOD is considered the likely respective, then vasodilator challenge with inhaled nitric oxide should be avoided, or undertaken with caution and low-dose administration, given multiple reports of severe pulmonary edema developing after vasodilator challenge in PVOD patients [9]. Thus, the diagnosis of PVOD is made from a combination of the above characteristics in the absence of left ventricular diastolic dysfunction, left-sided valve dysfunction, or any other identifiable cause for PH.

Despite advances in the management of patients with idiopathic PAH using vasodilator therapy, clinical improvement has not been seen in PVOD-related PAH, and many patients actually clinically deteriorate with the onset of severe pulmonary edema after initiation of such agents due to the obstruction in pulmonary venous outflow. Several recent reports have suggested that epoprostenol may play a role in bridging patients with PVOD to lung transplantation [9]. However, lung or heart-lung transplantation remains the only effective therapy, and patients should be referred to a transplantation center upon diagnosis.

Finally, other obstructive lesions to pulmonary venous drainage have been observed clinically and reported in the literature infrequently. Pulmonary vein stenosis is one of these lesions and can be either congenital or acquired. Acquired pulmonary vein stenosis has been noted after electrophysiologic ablation procedures and in patients with sclerosing mediastinitis. Also, cor triatriatum sinister and atrial myxoma have the potential to impair pulmonary venous drainage into the left atrium with the subsequent development of PH.

\section{Mitral Stenosis and Regurgitation}

Elevation of PA pressures is commonly observed in patients with both MS and MR. The presence or absence of $\mathrm{PH}$ with mitral valve disease is a key element in the decisionmaking algorithm for percutaneous or surgical intervention on the mitral valve in the most recent American College of Cardiology/American Heart Association Valvular Heart Disease guidelines [12].

The mechanism by which $\mathrm{PH}$ develops in patients with mitral valve disease is driven by an elevation of LA pressure, which in turn, leads to pulmonary venous hypertension, and subsequently, pulmonary arterial hypertension to deliver deoxygenated blood across the lungs from the right heart to the left heart. Left atrial compliance is often reduced resulting in an increased "v" wave in mitral valve disease. In patients with MS, the elevation in LA pressure also results from 


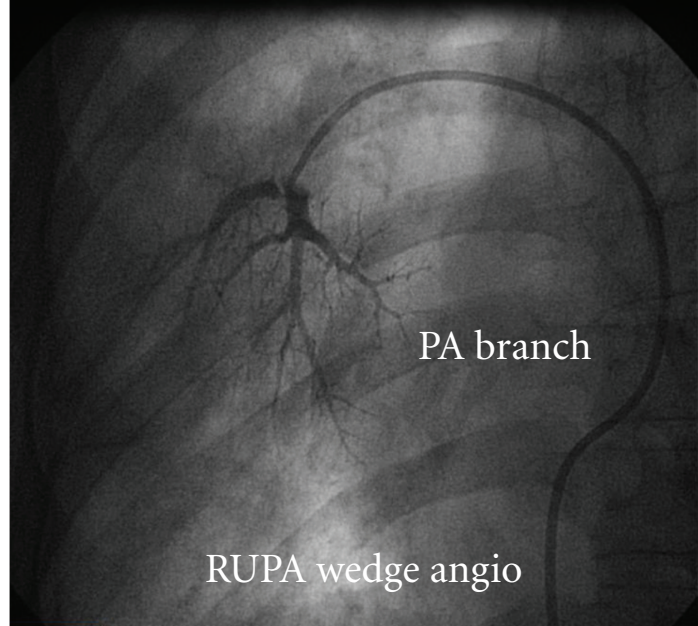

(a)

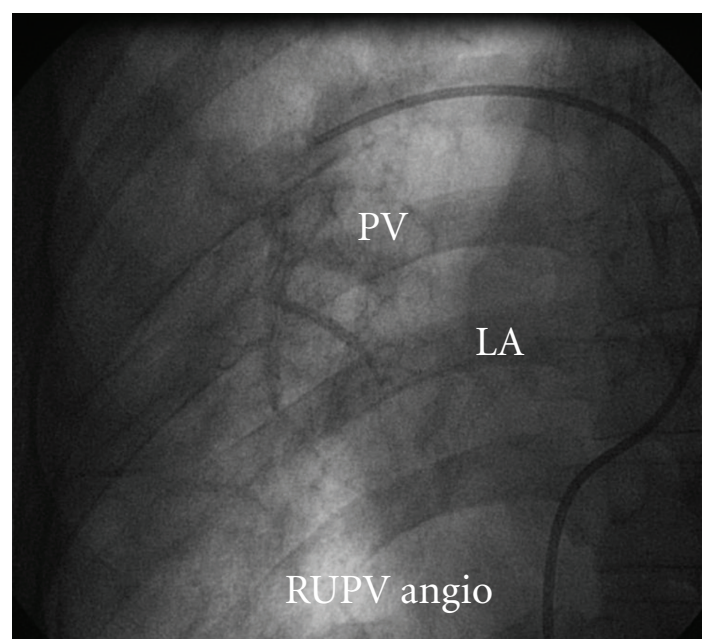

(c)

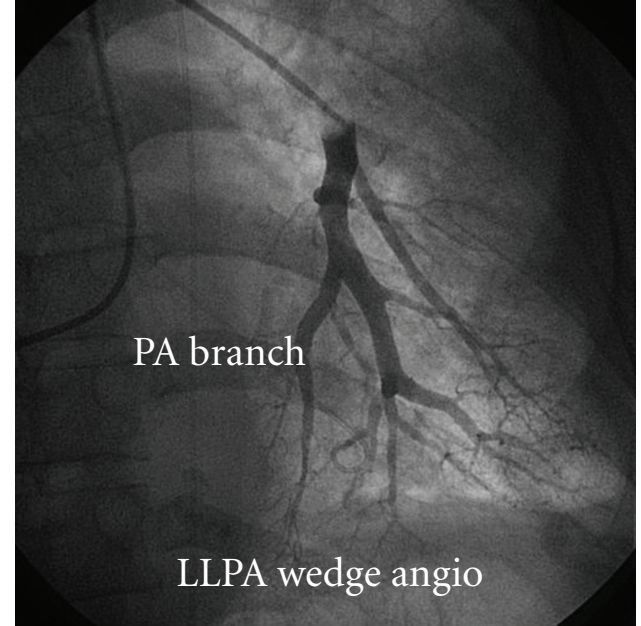

(b)

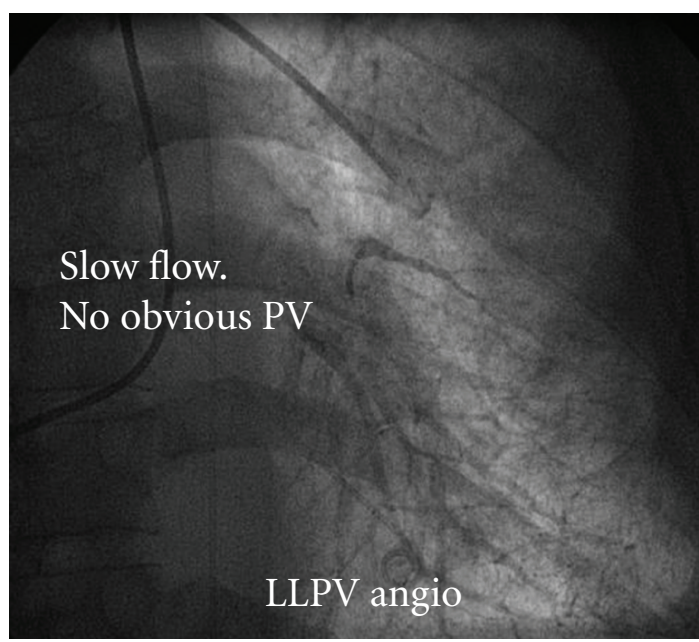

(d)

Figure 2: Pulmonary vein wedge angiography. In panel (a) balloon occlusion with hand contrast injection demonstrates opacification of the distal branches of the right upper pulmonary artery (RUPA) and in panel (b) the levophase of the wedge angiogram shows normal right upper pulmonary vein (RUPV) drainage into the left atrium (LA). Panel (c) shows normal opacification of the distal branches of the left lower pulmonary artery (LLPA) with wedge angiography. However, during the levophase in panel (d), there is abnormal drainage of the left lower pulmonary vein (LLPV) with contrast persisting in the LLPA and the absence of contrast media in the LA diagnostic of PVOD.

the abnormal diastolic pressure gradient across the dysfunctional mitral valve, while in patients with chronic MR, a further increase in LA pressure results from the regurgitant systolic jet and the rise in LV end-diastolic pressure.

With MS, there are two well-characterized associated hemodynamic states. Initially, with progression of MS, the mitral valve area (MVA) and cardiac output decrease with a concomitant rise in the LA pressure [13]. Later in disease progression, with a continued reduction in MVA and elevation of LA pressures, changes in the pulmonary vascular bed ensue, increasing the pulmonary vascular resistance and $\mathrm{PH}$. Often overt right heart failure occurs from right ventricular (RV) pressure overload [13]. Thus, the early stages of moderate to severe MS are associated with a decline in cardiac output due to one lesion at the level of the mitral valve. However, as the obstruction to LV filling by the stenotic mitral valve worsens with the onset of $\mathrm{PH}$, this "secondary stenosis" at the pulmonary bed level may lead to both low systemic cardiac output and RV failure.

Mitral stenosis, when moderate to severe, is associated with a variable degree of $\mathrm{PH}$ in the majority of patients. The pathophysiology of $\mathrm{PH}$ in MS involves structural alteration of the pulmonary vascular bed mediated by the potent vasoconstrictor endothelin-1 (ET-1) [14]. Levels of ET-1 are three-fold higher in patients with severe MS compared with healthy control subjects [14]. In a group of patients with severe MS undergoing PBMV or mitral valve replacement (MVR), the baseline ET-1 concentration is an independent predictor of a decrease in PCWP at 6 months following mitral valve intervention [14].

The American College of Cardiology (ACC)/American Heart Association (AHA) Valvular Heart Disease guidelines 
recommend intervention to relieve MS with percutaneous balloon mitral valvuloplasty (PBMV) if the valve morphology is favorable with a Wilkins score less than 8 and less than moderate MR, or surgical MVR, when $\mathrm{PH}$ is present [12]. More specifically, PBMV is advised for asymptomatic patients with moderate or severe MS and a resting PA systolic pressure greater than $50 \mathrm{~mm} \mathrm{Hg}$ or a PA systolic pressure greater than $60 \mathrm{~mm} \mathrm{Hg}$ and/or a PCWP greater than $25 \mathrm{~mm} \mathrm{Hg}$ with exercise [12]. For patients with NYHA class II-IV symptom status and moderate to severe MS, PBMV is recommended if the criteria above are met [12]. If valve morphology is not amenable to PBMV or there is also moderate to severe $M R$, then surgical valve replacement should be pursued even if severe $\mathrm{PH}$ is present [12].

A large body of outcome data exists for PBMV in mitral stenosis. Early work in the PBMV era showed that PA pressures fell immediately after PBMV, in concert with the reduction in mitral valve gradient [15]. In the immediate postprocedure period, PVR declined in this study population from 630 to 447 dynes $\times \mathrm{sec} / \mathrm{cm}^{5}$ and subsequently exhibited additional reduction to 280 dynes $\times \mathrm{sec} / \mathrm{cm}^{5}$ at 7 -month follow-up catheterization $[15,16]$. Further work in this area confirmed a reduction in PA pressures and PVR with PBMV $[17,18]$. Thus, one would expect relief of the MS by PBMV to reduce PA pressures to normal or near-normal levels in most patients. Following PBMV, surveillance for mitral valve restenosis with the return of $\mathrm{PH}$ is necessary. Appropriately selected patients with $\mathrm{PH}$ and MS should be referred to tertiary care centers with interventional experience in PBMV.

Surgical correction with mitral valve repair or replacement is the treatment of choice for chronic severe mitral regurgitation. For patients with increased predicted perioperative morbidity and mortality, percutaneous intervention with the MitraClip device may be considered. The most recent ACC/AHA management guidelines endorse mitral valve intervention if symptoms are present or in asymptomatic patients with a left ventricular ejection fraction (LVEF) less than 60\%, a left ventricular end-systolic diameter greater than $4 \mathrm{~cm}$, a resting PA systolic pressure greater than $50 \mathrm{~mm} \mathrm{Hg}$, or a PA systolic pressure greater than $60 \mathrm{~mm} \mathrm{Hg}$ with exercise [12].

Most of the clinical studies evaluating surgery for patients with mitral valve disease and PH included both MS and MR. Thus, the surgical outcomes for MS and MR will be reviewed together. Without relief of mitral valve obstruction, observational data from several decades ago demonstrated that mean survival was 2.4 years when severe PH was present with MS [19]. Several small, observational studies initially reported over forty years ago examined the changes in PA pressures pre- and postoperatively with right heart catheterization in patients with $\mathrm{PH}$ and mitral valve disease. One study detailed the hemodynamic findings in 31 patients before and at a mean of 7 months after Starr-Edwards prosthetic MVR [20]. In this study, PA systolic pressures declined from $75 \mathrm{~mm} \mathrm{Hg}$ to $39 \mathrm{~mm} \mathrm{Hg}$ with a concomitant increase in the cardiac index from 2.04 to 2.99 liters/minute/meter ${ }^{2}$ [20]. There was no difference in hemodynamic response to surgery between those with MS and MR. Similar work from the same era documented hemodynamic evaluation from a preoperative baseline over the course of 8-9 days postoperatively [21]. The mean PA pressures decreased from $71 \mathrm{~mm} \mathrm{Hg}$ to $35 \mathrm{~mm} \mathrm{Hg}$ with an increase in the cardiac index from 1.7 to 4.0 liters/minute/meter ${ }^{2}$ from baseline values to the end of the study period [21]. Another study from the same time period evaluated 25 patients at rest and with exercise to right heart catheterization preoperatively and at one year following Starr-Edwards prosthetic MVR [22]. This work reported a decline in PA pressures in $68 \%$ of patients and an improvement in cardiac index in the majority of patients one year after mitral valve surgery [22]. All patients in the series demonstrated persistent exercise-induced $\mathrm{PH}$, which in most, was related to increased gradients across the mitral valve during exercise [22].

Approximately 25 years after this original work, invasive hemodynamic evaluation from 22 patients with rheumatic mitral valve disease at preoperative baseline, and at 6 and 12 months following postoperative baseline was published [23]. This study demonstrated a significant diminution of PA systolic pressures and PCWP at rest and with exercise from baseline preoperative values to 6 months following surgery [23]. Furthermore, from 6 to 12 months postoperatively, there was an additional decrease in PA systolic pressures during exercise [23].

Finally, the acute hemodynamic response to bileaflet mechanical MVR was reported in 60 patients with $\mathrm{PH}$ from the modern era [24]. This publication evaluated 30 patients with mild PH (mean PA pressure of $29 \mathrm{~mm} \mathrm{Hg}$ ) and 30 patients with severe $\mathrm{PH}$ (mean PA pressure of $54 \mathrm{~mm} \mathrm{Hg}$ ) using invasive hemodynamic monitoring for 48 hours postoperatively [24]. In the cohort with mild $\mathrm{PH}$, the mean PA pressure fell to $16 \mathrm{~mm} \mathrm{Hg}$, while the cohort with severe PH had a mean PA pressure of $23 \mathrm{~mm} \mathrm{Hg}$ at 48 hours postoperatively [24]. Over 40 years of hemodynamic research suggests that most patients have an improvement in PA pressures to near-normal values following mitral valve surgery with some patients exhibiting normal resting pressures and persistent exercise-induced $\mathrm{PH}$.

Patients with $\mathrm{PH}$ secondary to mitral valve disease have been excluded from the clinical trials evaluating the current United States Food and Drug Administration (FDA)approved $\mathrm{PAH}$ pharmacologic vasodilator therapies. Case reports describing the safety and efficacy of various vasodilator agents during the immediate postoperative period in patients undergoing mitral valve surgery with preoperative PH have been published. The agents utilized include inhaled prostacyclin, inhaled nitric oxide, intravenous nitroprusside, and inhaled iloprost, and the reports focused on acute hemodynamic changes with the respective agents [25-29]. The pharmacologic mechanisms of these agents target different cellular pathways. Inhaled iloprost and epoprostenol are prostacyclin derivatives, which stimulate cyclic adenosine monophosphate (cAMP) production leading to pulmonary arterial smooth muscle relaxation [30]. In a similar manner, milrinone, a type 3 cAMP phosphodiesterase inhibitor, produces systemic and pulmonary arterial vasodilation by blocking the metabolism of cAMP in smooth muscle cells [31]. Through a different pathway with stimulation of cyclic guanylate monophosphate synthesis, inhaled nitric oxide 
and nitroprusside influence pulmonary arterial smooth muscle relaxation and vasodilation [30]. However, all of the agents are associated with a decrease in mean PA pressure, PVR, and with an increase in cardiac output. Moreover, one publication reports a greater likelihood for separation from cardiopulmonary bypass after mitral valve surgery in patients with $\mathrm{PH}$ treated with inhaled iloprost compared with no vasodilator therapy [29]. Pulmonary vasodilator agents appear safe for short-term administration in patients with $\mathrm{PH}$ during the perioperative mitral valve surgery period without any adverse events reported. Careful hemodynamic monitoring of the PCWP is necessary during administration to avoid the potential development of decompensated HF and pulmonary edema.

In addition, there are isolated case reports detailing the use of PAH pharmacotherapies as chronic therapy in patients with mitral valve disease and PH. The use of epoprostenol in this manner was reported in a patient with residual severe $\mathrm{PH}$ after MVR. There was an improvement in functional status and hemodynamics with a decrease in mean PA pressure and an increase in cardiac output [32]. Likewise, the successful use of the oral pulmonary vasodilator, sildenafil, following MVR in a patient with persistent severe $\mathrm{PH}$ has been noted [33]. The future role, if any, that conventional PAH drug therapy may play in the management of patients with $\mathrm{PH}$ and mitral valve disease that persists after surgery, or in patients who are not candidates for surgical or percutaneous intervention, remains to be determined through rigorous scientific evaluation.

\section{Aortic Stenosis}

Valvular AS is one of the most frequently encountered pathologies in the practice of adult cardiovascular medicine. However, the association of $\mathrm{PH}$ with severe AS is often underappreciated and varies with the threshold used for the detection of the presence of $\mathrm{PH}$. Aortic stenosis results in PH by creating LV diastolic dysfunction and subsequent pulmonary venous hypertension due to associated LV hypertrophy and reduced LV diastolic function. One of the original systematic characterizations of $\mathrm{PH}$ in patients with severe AS reported a prevalence for $\mathrm{PH}$ of $50 \%$ using the threshold of a PA systolic pressure of $>30 \mathrm{~mm} \mathrm{Hg}$ [34]. In this publication, PH was statistically associated with an elevated LVEDP [34]. Subsequently, using a cutoff value of a PA systolic pressure $>50 \mathrm{~mm} \mathrm{Hg}, 29 \%$ of patients with severe AS had concomitant PH [35]. More recently, in a cohort of nearly 400 patients with symptomatic severe AS, 50\% had mild to moderate $\mathrm{PH}$ with mean PA pressures of $31-50 \mathrm{~mm} \mathrm{Hg}$ and $15 \%$ had severe $\mathrm{PH}$ with a mean PA pressure $>50 \mathrm{~mm} \mathrm{Hg}$ [36]. Of note, in both of these studies, the majority of patients had an elevated transpulmonary gradient (TPG) suggesting that over time changes in the pulmonary vasculature had occurred leading to PH out-of-proportion to the PCWP/LVEDP.

Several echocardiographic studies have examined the relationship between severe AS and $\mathrm{PH}$. In a small study involving 50 patients with severe $\mathrm{AS}$ and $\mathrm{PH}$, multivariate analysis revealed that diastolic function as assessed by $\mathrm{E} / \mathrm{e}$ ' was the only independent predictor of $\mathrm{PH}$ [37]. However, in a larger study involving 626 patients, multivariate analysis showed that lower LVEF, severity of concomitant mitral regurgitation, smaller aortic valve area, and not taking a statin medication independently predicted PH [38]. These data suggest that additional left-sided cardiac pathology in addition to diastolic filling abnormalities may increase the likelihood for developing $\mathrm{PH}$ in patients with severe AS. Thus, careful hemodynamic evaluation is required to detect the presence of $\mathrm{PH}$ and any associated lesions given the increased surgical morbidity and mortality with aortic valve replacement when $\mathrm{PH}$ is present.

Surgical aortic valve replacement (AVR) is the recommended therapeutic intervention for patients with symptomatic, severe AS with a mean gradient greater than $40 \mathrm{~mm} \mathrm{Hg}$ or an aortic valve area less than $1.0 \mathrm{~cm}^{2}$ [12]. Likewise, AVR is advised in the asymptomatic patient when the LVEF is less than $50 \%$ [12]. However, perioperative morbidity and mortality increase significantly when $\mathrm{PH}$ is present. This is partly due to persistent pulmonary hypertension immediately after AVR, since LV diastolic dysfunction improves only after there is $\mathrm{LV}$ remodeling following AVR, and this may take several months.

In one study, the characteristics of 47 patients with severe AS and severe PH during the time period of 1987 to 1999 were analyzed, and the outcome demonstrated that perioperative mortality was $16 \%$ [39]. For the group of patients who had valve surgery and survived, PA pressures gradually declined, with an improvement in New York Heart Association (NYHA) class and LVEF [39]. The benefit from AVR, though, can be striking; a retrospective analysis of a cohort of 116 patients with severe AS and severe PH showed a 30day mortality of $8 \%$ in patients who had AVR versus $30 \%$ for those not having AVR [40]. This statistically significant survival difference persisted with $34 \%$ mortality in those who underwent AVR and $80 \%$ mortality in those without valve replacement at 5 year followup [40]. In addition, AVR was associated with a survival benefit after multivariate logistic regression analysis to control for other variables of comorbidity and with the use of a propensity score adjustment [40].

Based on analysis of nonrandomized, observational data, AVR in patients with severe $\mathrm{PH}$ and AS is associated with increased perioperative mortality compared to patients without PH. However, AVR is also associated with improved longterm survival and should be considered in selected patients at experienced, high-volume surgical centers. Based on the dramatic results of initial clinical trial data, transcatheter aortic valve replacement will also likely be an option in the future for patients with severe AS and $\mathrm{PH}$ who are at high risk for surgical AVR due to other comorbid conditions. At the present time, even isolated case reports on the use of pulmonary vasodilators in patients with severe $\mathrm{PH}$ and AS are lacking from the literature and the use of such agents cannot be recommended.

\section{Aortic Regurgitation}

Elevation of pulmonary artery pressures secondary to isolated aortic valve regurgitation (AR) is less common than 
with other valve lesions but does occur. Prior studies have reported a prevalence of $\mathrm{PH}$ in $10-20 \%$ of patients with severe AR [41]. The pathophysiology is explained by a chronic elevation of the LVEDP, which in turn, leads to an increase in LA and PA pressures or due to the acute elevation in LVEDP with acute severe AR (such as what might be observed in endocarditis or aortic dissection).

In chronic AR, surgery to replace the aortic valve is indicated when there are symptoms present with severe AR or with asymptomatic severe AR when the LVEF is less than $50 \%$ or there is dilation of the LV [12]. Retrospective analysis of 139 patients with $\mathrm{PH}$ and AR was reported nearly twenty years ago. This work observed that there was no significant difference in operative mortality or postoperative complications in patients undergoing AVR with severe $\mathrm{PH}$ and severe AR compared with mild or no $\mathrm{PH}$ and severe AR [42]. Furthermore, PA pressures declined to near-normal values in the vast majority of patients following AVR [42]. More recently, a single-center retrospective study of 506 patients with severe AR demonstrated that severe $\mathrm{PH}$ was statistically associated with lower LVEF, greater LV enddiastolic and end-systolic dimensions, and a higher grade of concomitant MR [41]. Moreover, multivariate analysis with propensity score adjustment showed an independent association between AVR and survival in patients with both severe PH and severe AR during 5 years of followup [41].

Although limited by potential selection bias, this work suggests that AVR can be performed with acceptable perioperative risk in patients with severe $\mathrm{PH}$ due to $\mathrm{AR}$. In addition, it also highlights the recurrent theme that valve surgery is often associated with a significant improvement in PA pressures and improved survival based on observational datasets.

\section{Left Ventricular Diastolic Dysfunction Associated with Preserved Systolic Left Ventricular Function}

Heart failure with preserved systolic function accounts for over half of hospitalizations for congestive heart failure. This category represents a varied group of disease states including systemic hypertension, hypertrophic cardiomyopathy, infiltrative cardiomyopathies, Fabry's disease, and obstructive sleep apnea. Some of these patients will develop $\mathrm{PH}$ as a response to the abnormal diastolic filling of the LV. Likewise, there is a growing population of elderly patients with dyspnea who have $\mathrm{PH}$ in which $\mathrm{HF}$ with preserved LVEF appears to be the most common cause [43]. The common link between all of these pathologies is the impairment of diastolic filling. Over time this leads to an increase in LA pressure in order to adequately fill the LV during diastole and a reduction in LA compliance. Subsequently, with the increase in LA pressure, there is a corresponding rise in PV and PA pressure. In some patients with long-standing elevation of LA pressure, the TPG gradient rises out of proportion to the LA pressure.

The epidemiology and association of $\mathrm{PH}$ in patients with normal LV function and diastolic dysfunction have been well recognized over the last decade. A recent population-based study of 244 patients with HF and preserved LVEF observed $\mathrm{PH}$ in $83 \%$ of patients as defined by an echocardiographic Doppler estimation of PA systolic pressure greater than $35 \mathrm{~mm} \mathrm{Hg}$ [5]. Furthermore, $\mathrm{PH}$ in patients with $\mathrm{HF}$ and preserved LV function has been found to be a strong predictor of mortality during a 2.8-year follow-up period [5]. This will likely be an increasing clinical problem in the coming years with the aging population and the epidemic of diabetes mellitus and obesity.

For the diagnosis of $\mathrm{PH}$ related to impaired diastolic filling, other potential causes of PH must be excluded. Right heart catheterization is obligatory and will usually reveal an elevated PCWP and LVEDP, mean PA pressure, and in some patients an elevated PVR with an exaggerated TPG gradient. Although not part of the diagnostic criteria in the $\mathrm{PH}$ guidelines, invasive hemodynamic evaluation with supine bicycle or arm weight exercises may occasionally be useful to better understand the symptomatic limitation of individual patients with suspected $\mathrm{PH}$ due to diastolic dysfunction [44].

At the present time, there are no guideline recommendations or clinical trial data regarding the management of $\mathrm{PH}$ in diastolic HF [1]. General guidance on the management of HF with preserved LV function has been published, however, emphasizing the importance of control of systemic blood pressure, rate control for atrial fibrillation if present, and diuretic usage if needed to avoid hypervolemia [45]. In the future, results from the currently enrolling Evaluating the Effectiveness of Sildenafil at Improving Health Outcomes and Exercise Ability in People with Diastolic Heart Failure (RELAX) trial may provide information on the use of sildenafil pulmonary vasodilator therapy in this specific patient population [46].

\section{Left Ventricular Diastolic Dysfunction Associated with Left Ventricular Systolic Dysfunction}

Pulmonary hypertension is commonly found in patients with left ventricular systolic dysfunction. It has been reported that two-thirds to three-fourths of patients with systolic heart failure (HF) due to ischemic or nonischemic cardiomyopathy have associated PH [31]. However, the presence or severity of $\mathrm{PH}$ does not correlate with LVEF [47]. The greatest predictors of $\mathrm{PH}$ in a population with $\mathrm{LV}$ systolic dysfunction are the grade of MR and mitral inflow E-wave deceleration time [48]. The latter reflects the rapid rise of LV diastolic pressure and decline in filling when there is diastolic dysfunction. Hence, the degree of LV systolic dysfunction is not the primary characteristic responsible for the development of $\mathrm{PH}$, but rather the degree of LV diastolic filling impairment and associated functional MR.

Greater understanding of the physiological mechanisms of $\mathrm{PH}$ in $\mathrm{HF}$ with systolic dysfunction has evolved over the last two decades. The circulating peptide ET- 1 is a potent vasoconstrictor and seems to play a role in the development of PH with MR. Elevated levels of circulating ET-1 in HF have been linked to higher PA pressures and PVR [49]. Moreover, ET-1 concentration has a strong positive correlation with 
NYHA class and a strong inverse relationship with LVEF and cardiac index [50]. Thus, the ET-1 receptor represents a logical therapeutic target.

Symptoms such as shortness of breath at rest and with exertion are a major manifestation of systolic HF, which negatively impact activity level and quality of life. In patients with a reduced LVEF, the concomitant presence of PH correlates with more advanced symptom status and greater functional impairment as reflected by a statistically higher NYHA class than a similar cohort with LV systolic dysfunction without PH [3]. This effect has been objectively documented with cardiopulmonary exercise (CPX) testing. CPX testing in 320 patients with an LVEF less than $40 \%$ demonstrated that cardiac output and peak oxygen consumption with exercise were significantly lower in those with an elevated PVR, further emphasizing the association of $\mathrm{PH}$ on symptom status and hemodynamics.

When $\mathrm{PH}$ is present with systolic HF, it is also associated with increased risk of death [51,52]. One study which followed 400 patients for 5 years estimated that there was a $9 \%$ increase in mortality for every $5 \mathrm{~mm} \mathrm{Hg}$ increase in right ventricular systolic pressure using Cox proportional hazards statistical analysis to adjust for other variable known to impact mortality [53]. Given the high mortality for patients with HF due to LV systolic dysfunction at 5 years, the development of $\mathrm{PH}$, which appears to further increase the risk of death, represents a serious problem.

Selected patients with advanced HF symptoms and severe LV systolic dysfunction are often considered for orthotopic heart transplantation. Multiple studies have examined the impact of $\mathrm{PH}$ on outcomes in patients undergoing transplant. The synthesis of the various studies shows that when a PVR greater than 2.5 Wood units and a TPG gradient greater than $15 \mathrm{~mm} \mathrm{Hg}$ is present, there is an increase in mortality at 3 month and 1 year posttransplant [47]. Mortality at one year posttransplant was $5.6 \%$ with a PVR less than 2.5 Wood units and a TPG gradient less than $15 \mathrm{~mm} \mathrm{Hg}$, while it was $24.4 \%$ in those with hemodynamics exceeding these threshold values [54]. Thus, $\mathrm{PH}$ with a PVR greater than 5 Wood units is a relative contraindication to transplant based on the International Society for Heart and Lung Transplantation guidelines [55]. Moreover, vasodilator challenge should be assessed during right heart catheterization to evaluate whether the elevated PVR is fixed or vasoreactive [55]. Observational data has shown that there is a significant reduction in mortality at 3 month posttransplant in patients with a pretransplant PVR $>2.5$ Wood units in whom the PVR decreased $<2.5$ Wood units with nitroprusside administration when compared to patients without such a decline in PVR (3.8\% versus 40.6\%) [56]. In a recent small pilot study, 6 pretransplant patients with a TPG gradient greater than $12 \mathrm{~mm} \mathrm{Hg}$, a PVR greater than 2.5 Wood units, and no reversibility with intravenous (IV) nitroprusside were given sildenafil for one month [57]. After one month of treatment, three patients demonstrated a normalization of TPG and PVR and 2 patients exhibited a decline in PA pressures with IV nitroprusside [57]. It is anticipated that future inquiry will expand our understanding of the use of pulmonary vasodilator therapies in the pretransplant population. Moreover, resolution or improvement in $\mathrm{PH}$ has also been reported in patients who have had recovery of LV function or who have undergone cardiac transplantation or left ventricular assist device (LVAD) placement.

There appears to be an expanding role for the LVAD as a bridge to heart transplant in the management of patients with severe left ventricular systolic $\mathrm{HF}$ and $\mathrm{PH}$. Several studies in patients with systolic $\mathrm{HF}$ and severe $\mathrm{PH}$ have demonstrated that an elevated PVR despite pharmacologic therapy is often reduced to $<2.5$ Wood units over a 6 month time period following LVAD placement [58-62]. Retrospective, observational data analysis has also established that in patients in whom the pulmonary pressure improves with LVAD therapy as bridge to transplant, there is no statistical difference in subsequent posttransplant survival compared to patients without $\mathrm{PH}[60,61]$. The beneficial actions of the LVAD undoubtedly relate to afterload reduction of the LV and a reduction in the PCWP with corresponding reductions in the mean PA pressure and PVR. Improvement in the PVR has been reported with both pulsatile flow devices and newer, continuous flow LVADs [63]. Given the strong correlation of an elevated PVR and an adverse outcome following orthotopic heart transplant, the use of LVAD therapy to reduce the PVR prior to transplant may improve the transplant outcomes in these patients.

Although there are no FDA-approved agents for the treatment of PH due to LV systolic dysfunction, the use of longterm pulmonary vasodilator therapy has been attempted to improve symptoms. Early work in this area with chronic epoprostenol administration in the Flolan International Randomized Survival trial (FIRST), however, observed an increased mortality in the cohort with LV systolic dysfunction; the trial was terminated early by the Data Safety Monitoring board [64]. Subsequently, small series have investigated the efficacy and hemodynamic actions of other vasodilator therapies in patients with systolic HF and PH. As described earlier, endothelin-1 likely plays an important role in the pathophysiology of $\mathrm{PH}$ in this setting. Therefore, drugs targeting inhibition of the endothelin receptor have been developed and are approved for chronic therapy in idiopathic PAH. Unfortunately, long-term studies involving the endothelin receptor antagonists, darusentan and bosentan, have not shown any beneficial actions on LV chamber size, or neurohormonal levels with darusentan, or on symptoms with bosentan $[65,66]$. Another agent, nesiritide, a recombinant version of human brain natriuretic peptide, has also been extensively studied with mixed results. One of the hemodynamic actions of nesiritide is to decrease the PCWP, the mean PA pressure, and PVR acutely with short-term infusion [67].

Milrinone, an inhibitor of type 3 phosphodiesterase, is an inotrope and systemic vasodilator used in the management of acute decompensated HF from LV systolic dysfunction. It also has hemodynamic actions on the pulmonary vasculature by decreasing PVR and augmenting RV function [68]. In clinical practice, it is used in selected patients as a bridge to transplant or in the perioperative period after LVAD placement in patients with systolic $\mathrm{HF}$ and $\mathrm{PH}$. 
Finally, the type 5 phosphodiesterase inhibitor, sildenafil, which is approved for chronic therapy of idiopathic PAH, has been evaluated in $\mathrm{PH}$ with systolic HF. During a 6 month randomized trial of sildenafil or placebo in 46 patients with mild $\mathrm{PH}$ and systolic HF, there was statistically significant reduction in PA pressures and an increase in peak oxygen consumption during CPX testing, without adverse side effects reported [69]. Similarly, the randomization of 34 patients to sildenafil or placebo showed an improvement in PVR, peak oxygen consumption during CPX testing, 6minute walk duration, and quality of life with sildenafil therapy at 3 months [70]. Larger scale clinical trials with longer followup are needed, though, to determine what role, if any, sildenafil will play in the management of $\mathrm{PH}$ in systolic HF. The cornerstone of therapy for patients with PH and LV systolic dysfunction remains evidence-based HF therapies such as beta-blockers, angiotensin-converting enzyme inhibitors, and aldosterone antagonists, which reduce afterload on the $\mathrm{LV}$ and influence favorable myocardial remodeling leading to improved LV diastolic properties, and in turn, lower LA pressure with a corresponding reduction in PA pressures.

\section{Conclusion}

In conclusion, $\mathrm{PH}$ frequently develops in response to leftsided cardiac disease due to elevated pulmonary venous pressure and is associated with a series of lesions that range from diseases of the pulmonary veins, mechanical obstruction in the LA or at the mitral valve, or to elevation in the left atrial and pulmonary venous pressure due to mitral regurgitation, abnormal LA compliance, or to LV diastolic dysfunction. In some patients, secondary pulmonary hypertension appears to occur in addition. Pulmonary hypertension is associated with increased morbidity and mortality. In the setting of $\mathrm{PH}$-related to left-sided obstructive or regurgitant valve disease, the PA pressures commonly decrease significantly or return to normal after valve replacement, repair, or mitral valvuloplasty; unfortunately this does not occur in all.

For patients with left ventricular systolic/diastolic dysfunction, the prognosis and options for treatment of associated pulmonary hypertension independent of therapy for the left heart disease are less favorable. Although not included in the vast majority of PAH vasodilator therapy clinical trials, vasodilator therapy may be of clinical benefit in a few carefully selected patients with left-sided cardiac disease in whom $\mathrm{PH}$ does not improve after addressing the underlying cardiac pathology.

\section{References}

[1] V. V. McLaughlin, S. L. Archer, D. B. Badesch et al., "ACCF/ AHA 2009 expert consensus document on pulmonary hypertension. A report of the American College of Cardiology Foundation task force on expert consensus documents and the American Heart Association Developed in Collaboration with the American College of Chest Physicians; American Thoracic Society, Inc.; and the Pulmonary Hypertension Association," Journal of the American College of Cardiology, vol. 53, no. 17, pp. 1573-1619, 2009.
[2] N. Gali, M. M. Hoeper, M. Humbert et al., "Guidelines for the diagnosis and treatment of pulmonary hypertension," European Heart Journal, vol. 30, no. 20, pp. 2493-2537, 2009.

[3] S. Ghio, A. Gavazzi, C. Campana et al., "Independent and additive prognostic value of right ventricular systolic function and pulmonary artery pressure in patients with chronic heart failure," Journal of the American College of Cardiology, vol. 37, no. 1, pp. 183-188, 2001.

[4] F. Grigioni, L. Potena, N. Galiè et al., "Prognostic implications of serial assessments of pulmonary hypertension in severe chronic heart failure," Journal of Heart and Lung Transplantation, vol. 25, no. 10, pp. 1241-1246, 2006.

[5] C. S. P. Lam, V. L. Roger, R. J. Rodeheffer, B. A. Borlaug, F. T. Enders, and M. M. Redfield, "Pulmonary hypertension in heart failure with preserved ejection fraction. A communitybased study," Journal of the American College of Cardiology, vol. 53, no. 13, pp. 1119-1126, 2009.

[6] M. C. Walls, N. Cimino, S. F. Bolling, and D. S. Bach, "Persistent pulmonary hypertension after mitral valve surgery: does surgical procedure affect outcome?" The Journal of Heart Valve Disease, vol. 17, no. 1, pp. 1-9, 2008.

[7] R. A. Krasuski, J. J. Warner, A. Wang, J. K. Harrison, V. F. Tapson, and T. M. Bashore, "Inhaled nitric oxide selectively dilates pulmonary vasculature in adult patients with pulmonary hypertension, irrespective of etiology," Journal of the American College of Cardiology, vol. 36, no. 7, pp. 2204-2211, 2000.

[8] R. A. Krasuski, A. Wang, J. K. Harrison, V. F. Tapson, and T. M. Bashore, "The response to inhaled nitric oxide in patients with pulmonary artery hypertension is not masked by baseline vasodilator use," American Heart Journal, vol. 150, no. 4, pp. 725-728, 2005.

[9] D. Montani, D. S. O'Callaghan, L. Savale et al., "Pulmonary veno-occlusive disease: recent progress and current challenges," Respiratory Medicine, vol. 104, supplement 1, pp. S23S32, 2010.

[10] M. Palazzini and A. Manes, "Pulmonary veno-occlusive disease misdiagnosed as idiopathic pulmonary arterial hypertension," European Respiratory Review, vol. 18, no. 113, pp. 177180, 2009.

[11] D. Montani, L. Achouh, P. Dorfmüller et al., "Pulmonary veno-occlusive disease: clinical, functional, radiologic, and hemodynamic characteristics and outcome of 24 cases confirmed by histology," Medicine, vol. 87, no. 4, pp. 220-233, 2008.

[12] R. O. Bonow, B. A. Carabello, K. Chatterjee et al., "2008 focused update incorporated into the ACC/AHA 2006 guidelines for the management of patients with valvular heart disease. A report of the American College of Cardiology/American Heart Association task force on practice guidelines (Writing Committee to Revise the 1998 Guidelines for the Management of Patients With Valvular Heart Disease)," Journal of the American College of Cardiology, vol. 52, no. 13, pp. e1-e142, 2008.

[13] W. Feldman TaG, "Profiles in valvular heart disease," in Grossman's Cardiac Catheterization, Angiography, and Intervention, D. S. Baim, Ed., pp. 637-638, Lippincott Williams \& Wilkins, Philadelphia, Pa, USA, 7th edition, 2006.

[14] G. Snopek, H. Pogorzelska, T. M. Rywik, A. Browarek, J. Janas, and J. Korewicki, "Usefulness of endothelin-1 concentration in capillary blood in patients with mitral stenosis as a predictor of regression of pulmonary hypertension after mitral valve replacement or valvuloplasty," American Journal of Cardiology, vol. 90, no. 2, pp. 188-189, 2002. 
[15] M. J. Levine, J. S. Weinstein, D. J. Diver et al., "Progressive improvement in pulmonary vascular resistance after percutaneous mitral valvuloplasty," Circulation, vol. 79, no. 5, pp. 1061-1067, 1989.

[16] P. A. Ribeiro, M. A. Zaibag, and M. Abdullah, "Pulmonary artery pressure and pulmonary vascular resistance before and after mitral balloon valvotomy in 100 patients with severe mitral valve stenosis," American Heart Journal, vol. 125, no. 4, pp. 1110-1114, 1993.

[17] J. S. Hung, M. S. Chern, J. J. Wu et al., "Short- and long-term results of catheter balloon percutaneous transvenous mitral commissurotomy," American Journal of Cardiology, vol. 67, no. 9, pp. 854-862, 1991.

[18] V. Dev and S. Shrivastava, "Time course of changes in pulmonary vascular resistance and the mechanism of regression of pulmonary arterial hypertension after balloon mitral valvuloplasty," American Journal of Cardiology, vol. 67, no. 5, pp. 439-442, 1991.

[19] C. Ward and B. W. Hancock, "Extreme pulmonary hypertension caused by mitral valve disease. Natural history and results of surgery," British Heart Journal, vol. 37, no. 1, pp. 74-78, 1975.

[20] E. Braunwald, N. S. Braunwald, J. Ross Jr., and A. G. Morrow, "Effects of mitral-valve replacement on the pulmonary vascular dynamics of patients with pulmonary hypertension," The New England Journal of Medicine, vol. 273, pp. 509-514, 1965.

[21] J. E. Dalen, J. M. Matloff, G. L. Evans et al., "Early reduction of pulmonary vascular resistance after mitral-valve replacement," The New England Journal of Medicine, vol. 277, no. 8, pp. 387394, 1967.

[22] J. J. Morgan, "Hemodynamics one year following mitral valve replacement," The American Journal of Cardiology, vol. 19, no. 2, pp. 189-195, 1967.

[23] T. Zielinski, H. Pogorzelska, A. Rajecka, A. Biedermavn, M. Sliwinski, and J. Korewicki, "Pulmonary hemodynamics at rest and effort, 6 and 12 months after mitral valve replacement: a slow regression of effort pulmonary hypertension," International Journal of Cardiology, vol. 42, no. 1, pp. 57-62, 1993.

[24] D. K. Tempe, S. Hasija, V. Datt et al., "Evaluation and comparison of early hemodynamic changes after elective mitral valve replacement in patients with severe and mild pulmonary arterial hypertension," Journal of Cardiothoracic and Vascular Anesthesia, vol. 23, no. 3, pp. 298-305, 2009.

[25] K. Fattouch, F. Sbraga, G. Bianco et al., "Inhaled prostacyclin, nitric oxide, and nitroprusside in pulmonary hypertension after mitral valve replacement," Journal of Cardiac Surgery, vol. 20, no. 2, pp. 171-176, 2005.

[26] F. Santini, G. Casali, G. Franchi et al., "Hemodynamic effects of inhaled nitric oxide and phosphodiesterase inhibitor (dipyridamole) on secondary pulmonary hypertension following heart valve surgery in adults," International Journal of Cardiology, vol. 103, no. 2, pp. 156-163, 2005.

[27] D. G. Healy, D. Veerasingam, J. McHale, and D. Luke, "Successful perioperative utilisation on inhaled nitric oxide in mitral valve surgery," Journal of Cardiovascular Surgery, vol. 47, no. 2, pp. 217-220, 2006.

[28] N. Yurtseven, P. Karaca, G. Uysal et al., "A comparison of the acute hemodynamic effects of inhaled nitroglycerin and iloprost in patients with pulmonary hypertension undergoing mitral valve surgery," Annals of Thoracic and Cardiovascular Surgery, vol. 12, no. 5, pp. 319-323, 2006.

[29] S. Rex, G. Schaelte, S. Metzelder et al., "Inhaled iloprost to control pulmonary artery hypertension in patients undergoing mitral valve surgery: a prospective, randomized-controlled trial," Acta Anaesthesiologica Scandinavica, vol. 52, no. 1, pp. 65-72, 2008.

[30] M. D. McGoon and G. C. Kane, "Pulmonary hypertension: diagnosis and management," Mayo Clinic Proceedings, vol. 84, no. 2, pp. 191-207, 2009.

[31] R. V. Shah and M. J. Semigran, "Pulmonary hypertension secondary to left ventricular systolic dysfunction: contemporary diagnosis and management," Current Heart Failure Reports, vol. 5, no. 4, pp. 226-232, 2008.

[32] C. G. Elliott and H. I. Palevsky, "Treatment with epoprostenol of pulmonary arterial hypertension following mitral valve replacement for mitral stenosis," Thorax, vol. 59, no. 6, pp. 536-537, 2004.

[33] C. Bomma, H. O. Ventura, G. Daniel, and H. Patel, "Adjunctive sildenafil for the treatment of pulmonary hypertension after mitral valve replacement," Congestive Heart Failure, vol. 12, no. 6, pp. 347-348, 2006.

[34] L. W. Johnson, M. B. Hapanowicz, C. Buonanno, M. A. Bowser, M. A. Marvasti, and F. B. Parker, "Pulmonary hypertension in isolated aortic stenosis. Hemodynamic correlations and follow-up," Journal of Thoracic and Cardiovascular Surgery, vol. 95, no. 4, pp. 603-607, 1988.

[35] K. Silver, G. Aurigemma, S. Krendel, N. Barry, I. Ockene, and J. Alpert, "Pulmonary artery hypertension in severe aortic stenosis: incidence and mechanism," American Heart Journal, vol. 125, no. 1, pp. 146-150, 1993.

[36] P. Faggiano, F. Antonini-Canterin, F. Ribichini et al., "Pulmonary artery hypertension in adult patients with symptomatic valvular aortic stenosis," American Journal of Cardiology, vol. 85, no. 2, pp. 204-208, 2000.

[37] G. Casaclang-Verzosa, V. T. Nkomo, M. E. Sarano, J. F. Malouf, F. A. Miller, and J. K. Oh, "E/Ea is the major determinant of pulmonary artery pressure in moderate to severe aortic stenosis," Journal of the American Society of Echocardiography, vol. 21, no. 7, pp. 824-827, 2008.

[38] N. Kapoor, P. Varadarajan, and R. G. Pai, "Echocardiographic predictors of pulmonary hypertension in patients with severe aortic stenosis," European Journal of Echocardiography, vol. 9, no. 1, pp. 31-33, 2008.

[39] J. F. Malouf, M. Enriquez-Sarano, P. A. Pellikka et al., "Severe pulmonary hypertension in patients with severe aortic valve stenosis: clinical profile and prognostic implications," Journal of the American College of Cardiology, vol. 40, no. 4, pp. 789795, 2002.

[40] R. G. Pai, P. Varadarajan, N. Kapoor, and R. C. Bansal, "Aortic valve replacement improves survival in severe aortic stenosis associated with severe pulmonary hypertension," Annals of Thoracic Surgery, vol. 84, no. 1, pp. 80-85, 2007.

[41] S. Khandhar, P. Varadarajan, R. Turk et al., "Survival benefit of aortic valve replacement in patients with severe aortic regurgitation and pulmonary hypertension," Annals of Thoracic Surgery, vol. 88, no. 3, pp. 752-756, 2009.

[42] D. P. Naidoo, A. S. Mitha, S. Vythilingum, and S. Chetty, "Pulmonary hypertension in aortic regurgitation: early surgical outcome," Quarterly Journal of Medicine, vol. 80, no. 291, pp. 589-595, 1991.

[43] B. P. Shapiro, M. D. McGoon, and M. M. Redfield, "Unexplained pulmonary hypertension in elderly patients," Chest, vol. 131, no. 1, pp. 94-100, 2007.

[44] B. A. Borlaug, R. A. Nishimura, P. Sorajja, C. S. P. Lam, and M. M. Redfield, "Exercise hemodynamics enhance diagnosis of early heart failure with preserved ejection fraction," Circulation: Heart Failure, vol. 3, no. 5, pp. 588-595, 2010. 
[45] S. A. Hunt, W. T. Abraham, M. H. Chin et al., "2009 focused update incorporated Into the ACC/AHA 2005 guidelines for the diagnosis and management of heart failure in adults. A report of the American College of Cardiology Foundation/American Heart Association task force on practice guidelines developed in collaboration with the International Society for Heart and Lung Transplantation," Journal of the American College of Cardiology, vol. 53, no. 15, pp. e1-e90, 2009.

[46] Evaluating the Effectiveness of Sildenafil at Improving Health Outcomes and Exercise Ability in People with Diastolic Heart Failure (The RELAX Study), 2010, http://clinicaltrials .gov/ct2/show/NCT00763867?term $=$ relax\&rank=00763861.

[47] M. Guglin and H. Khan, "Pulmonary hypertension in heart failure," Journal of Cardiac Failure, vol. 16, no. 6, pp. 461-474, 2010.

[48] F. L. Dini, R. Nuti, L. Barsotti, U. Baldini, R. Dell'Anna, and G. Micheli, "Doppler-derived mitral and pulmonary venous flow variables are predictors of pulmonary hypertension in dilated cardiomyopathy," Echocardiography, vol. 19, no. 6, pp. 457465, 2002.

[49] R. J. Cody, G. J. Haas, P. F. Binkley, Q. Capers, and R. Kelley, "Plasma endothelin correlates with the extent of pulmonary hypertension in patients with chronic congestive heart failure," Circulation, vol. 85, no. 2, pp. 504-509, 1992.

[50] C. M. Wei, A. Lerman, R. J. Rodeheffer et al., "Endothelin in human congestive heart failure," Circulation, vol. 89, no. 4, pp. 1580-1586, 1994.

[51] S. V. Abramson, J. F. Burke, J. J. Kelly et al., "Pulmonary hypertension predicts mortality and morbidity in patients with dilated cardiomyopathy," Annals of Internal Medicine, vol. 116, no. 11, pp. 888-895, 1992.

[52] T. P. Cappola, G. M. Felker, W. H. L. Kao, J. M. Hare, K. L. Baughman, and E. K. Kasper, "Pulmonary hypertension and risk of death in cardiomyopathy: patients with myocarditis are at higher risk," Circulation, vol. 105, no. 14, pp. 1663-1668, 2002.

[53] J. Kjaergaard, D. Akkan, K. K. Iversen et al., "Prognostic importance of pulmonary hypertension in patients with heart failure," American Journal of Cardiology, vol. 99, no. 8, pp. 1146-1150, 2007.

[54] J. F. Delgado, M. A. Gomez-Sanchez, C. Saenz de la Calzada et al., "Impact of mild pulmonary hypertension on mortality and pulmonary artery pressure profile after heart transplantation," Journal of Heart and Lung Transplantation, vol. 20, no. 9, pp. 942-948, 2001.

[55] M. R. Mehra, J. Kobashigawa, R. Starling et al., "Listing criteria for heart transplantation: International Society for Heart and Lung Transplantation guidelines for the care of cardiac transplant candidates-2006," Journal of Heart and Lung Transplantation, vol. 25, no. 9, pp. 1024-1042, 2006.

[56] A. Costard-Jackle and M. B. Fowler, "Influence of preoperative pulmonary artery pressure on mortality after heart transplantation: testing of potential reversibility of pulmonary hypertension with nitroprusside is useful in defining a high risk group," Journal of the American College of Cardiology, vol. 19, no. 1, pp. 48-54, 1992.

[57] M. Zakliczynski, M. Maruszewski, L. Pyka et al., "Effectiveness and safety of treatment with sildenafil for secondary pulmonary hypertension in heart transplant candidates," Transplantation Proceedings, vol. 39, no. 9, pp. 2856-2858, 2007.
[58] J. Martin, M. P. Siegenthaler, O. Friesewinkel et al., "Implantable left ventricular assist device for treatment of pulmonary hypertension in candidates for orthotopic heart transplantation-a preliminary study," European Journal of Cardio-Thoracic Surgery, vol. 25, no. 6, pp. 971-977, 2004.

[59] S. P. Salzberg, M. L. Lachat, K. von Harbou, G. Zünd, and M. I. Turina, "Normalization of high pulmonary vascular resistance with LVAD support in heart transplantation candidates," European Journal of Cardio-Thoracic Surgery, vol. 27, no. 2, pp. 222-225, 2005.

[60] H. Liden, A. Haraldsson, S.-E. Ricksten, U. Kjellman, and L. Wiklund, "Does pretransplant left ventricular assist device therapy improve results after heart transplantation in patients with elevated pulmonary vascular resistance?" European Journal of Cardio-Thoracic Surgery, vol. 35, no. 6, pp. 1029-1035, 2009.

[61] A. C. Alba, V. Rao, H. J. Ross et al., "Impact of fixed pulmonary hypertension on post-heart transplant outcomes in bridge-totransplant patients," Journal of Heart and Lung Transplantation, vol. 29, no. 11, pp. 1253-1258, 2010.

[62] E. Mikus, A. Stepanenko, T. Krabatsch et al., "Reversibility of fixed pulmonary hypertension in left ventricular assist device support recipients," European Journal of Cardio-thoracic Surgery. In Press.

[63] R. John, K. Liao, F. Kamdar, P. Eckman, A. Boyle, and M. Colvin-Adams, "Effects on pre- and posttransplant pulmonary hemodynamics in patients with continuous-flow left ventricular assist devices," Journal of Thoracic and Cardiovascular Surgery, vol. 140, no. 2, pp. 447-452, 2010.

[64] R. M. Califf, K. F. Adams, W. J. McKenna et al., "A randomized controlled trial of epoprostenol therapy for severe congestive heart failure: the Flolan International Randomized Survival Trial (FIRST)," American Heart Journal, vol. 134, no. 1, pp. 4454, 1997.

[65] P. I. Anand, P. J. McMurray, P. J. N. Cohn et al., "Longterm effects of darusentan on left-ventricular remodelling and clinical outcomes in the EndothelinA Receptor Antagonist Trial in Heart Failure (EARTH): randomised, double-blind, placebo-controlled trial," The Lancet, vol. 364, no. 9431, pp. 347-354, 2004.

[66] M. Packer, J. McMurray, B. M. Massie et al., "Clinical effects of endothelin receptor antagonism with bosentan in patients with severe chronic heart failure: results of a pilot study," Journal of Cardiac Failure, vol. 11, no. 1, pp. 12-20, 2005.

[67] W. S. Colucci, U. Elkayam, D. P. Horton et al., "Intravenous nesiritide, a natriuretic peptide, in the treatment of decompensated congestive heart failure," The New England Journal of Medicine, vol. 343, no. 4, pp. 246-253, 2000.

[68] M. R. Mehra, H. O. Ventura, C. Kapoor, D. D. Stapleton, D. Zimmerman, and F. W. Smart, "Safety and clinical utility of long-term intravenous milrinone in advanced heart failure," American Journal of Cardiology, vol. 80, no. 1, pp. 61-64, 1997.

[69] G. D. Lewis, R. Shah, K. Shahzad et al., "Sildenafil improves exercise capacity and quality of life in patients with systolic heart failure and secondary pulmonary hypertension," Circulation, vol. 116, no. 14, pp. 1555-1562, 2007.

[70] M. Guazzi, M. Samaja, R. Arena, M. Vicenzi, and M. D. Guazzi, "Long-term use of sildenafil in the therapeutic management of heart failure," Journal of the American College of Cardiology, vol. 50, no. 22, pp. 2136-2144, 2007. 


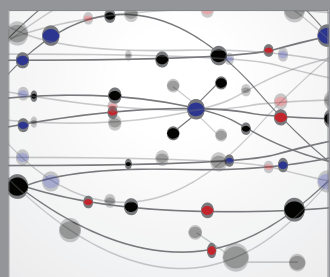

The Scientific World Journal
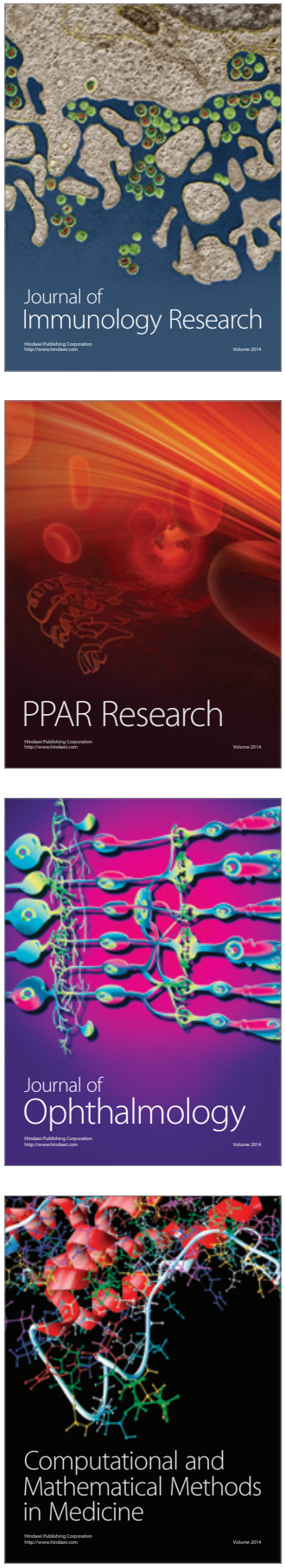

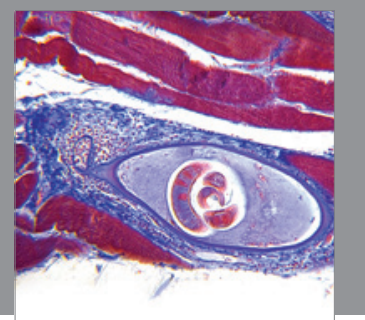

Gastroenterology

Research and Practice
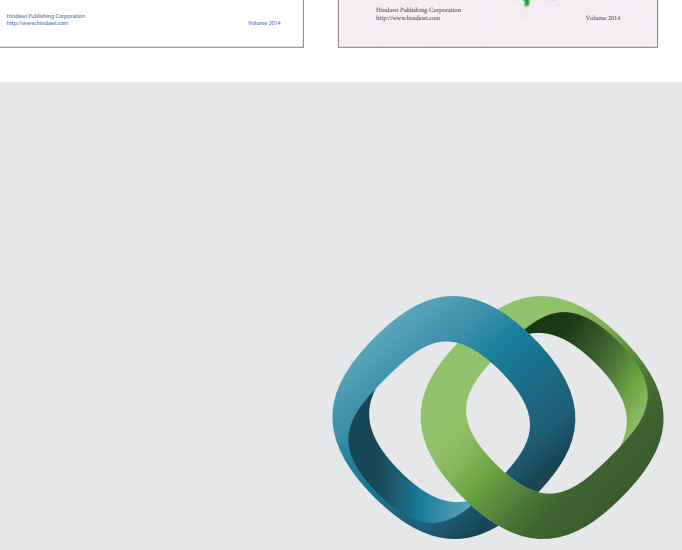

\section{Hindawi}

Submit your manuscripts at

http://www.hindawi.com
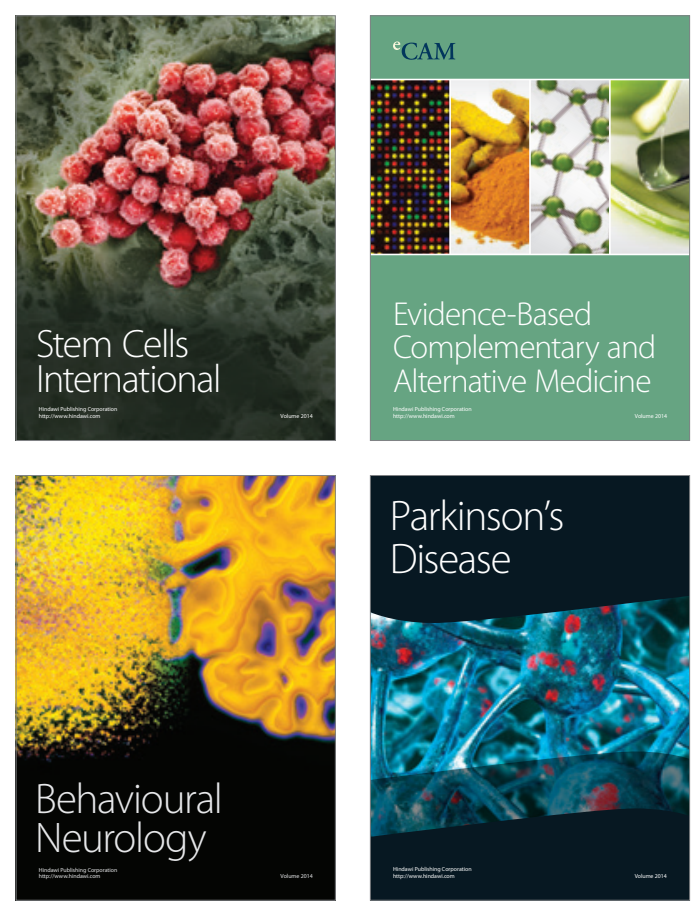

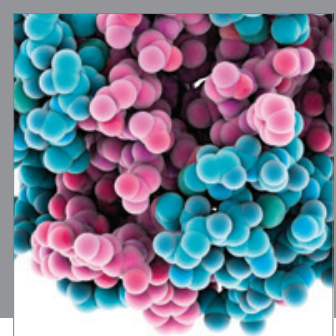

Journal of
Diabetes Research

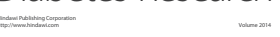

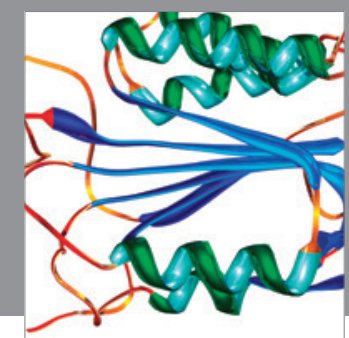

Disease Markers
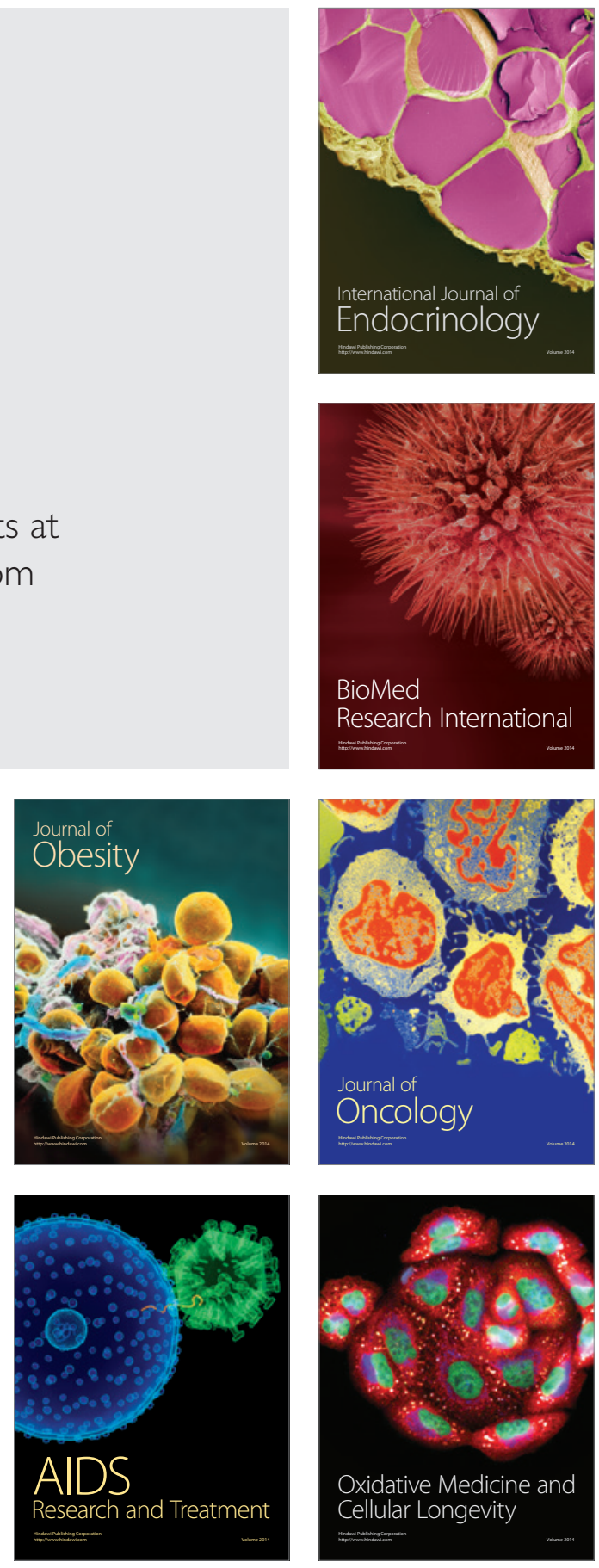